Case Report

\title{
Diagnosis and Management's Distinctive Features of an Ectopic Spleen in a Precarious Country
}

\author{
Solonirina Davidà Rakotomena ${ }^{1,}$,, Narindra Njarasoa Mihaja Razafimanjato ${ }^{2}$, \\ Kanto Adrienne Razafindraibe ${ }^{3}$, Auberlin Felantsoa Rakototiana ${ }^{4}$, Hery Nirina Rakoto-Ratsimba ${ }^{1}$ \\ ${ }^{1}$ Department of Visceral Surgery, Joseph Ravoahangy Andrianavalona University Hospital Center, Antananarivo, Madagascar \\ ${ }^{2}$ Department of Thoracic Surgery, Joseph Ravoahangy Andrianavalona University Hospital Center, Antananarivo, Madagascar \\ ${ }^{3}$ Department of Medical Imaging, Joseph Ravoahangy Andrianavalona University Hospital Center, Antananarivo, Madagascar \\ ${ }^{4}$ Department of Urology, Joseph Ravoahangy Andrianavalona University Hospital Center, Antananarivo, Madagascar \\ Email address: \\ rakotomenadavida@yahoo.fr (S. D. Rakotomena), razafesteban@yahoo.fr (N. N. M. Razafimanjato), \\ andriatsimbakanto@gmail.com (K. A. Razafindraibe), drauberlin@yahoo.fr (A. F. Rakototiana), rrhery@yahoo.fr (H. N. Rakoto-Ratsimba) \\ ${ }^{*}$ Corresponding author
}

\section{To cite this article:}

Solonirina Davidà Rakotomena, Narindra Njarasoa Mihaja Razafimanjato, Kanto Adrienne Razafindraibe, Auberlin Felantsoa Rakototiana, Hery Nirina Rakoto-Ratsimba. Diagnosis and Management's Distinctive Features of an Ectopic Spleen in a Precarious Country. European Journal of Clinical and Biomedical Sciences. Vol. 5, No. 6, 2019, pp. 89-91. doi: 10.11648/j.ejcbs.20190506.14

Received: November 19, 2019; Accepted: December 9, 2019; Published: December 30, 2019

\begin{abstract}
Abdominal or pelvic ectopic spleen or wandering spleen or drifting spleen is extremely rare. It is a consequence of congenital or acquired laxity of this organ's attachment to the diaphragmatic dome, especially the suspensor ligament. The authors report a new typical case of this pathology in a 27-year-old woman, having came to consultation for painfull pelvic mass in the Joseph Ravoahangy Andrianavalona University Hospital Center in Antananarivo Madagascar, which is a precarious country. The positive diagnostic of this pathology and its surgical approach are often limited by the locally available tools and the financial accessibility of the patient to them. Ultrasonography and Computed Tomography imaging show the emptiness of the splenic lodge, localize the spleen with its size, and precise its vascularisation's pathway. The symptoms are naturally latent until complication appears. Surgery is more formally indicated in case of complication or because of the risk of confusion with parasitic splenomegaly which has a high prevalence in a tropical country as Madagascar. Splenopexy can exposes to more recurrences, systemacic splenectomy can expose to risks of more postoperative infection even it is more practiced. As proposed in the literature, laparoscopy could and should be developed because it does not have any eventful recovery.
\end{abstract}

Keywords: Diagnostic Imaging, Ectopic Spleen, Wandering Spleen, Surgical Approach, Precarious Country

\section{Introduction}

Any healthy or pathological spleen is ectopic when located outside its normal location, when superior pole is devoid of its attaches with the diaphragmatic dome [1]. Issued to embryonic development, splenophrenic and splenoomental ligaments are inconstant, but gastrosplenic, splenorenal and splenocolic ligaments never exist in wandering spleen [1-3]. Its migration, congenital or acquired, to any quadrant of the abdomen or pelvis depends on the length of its pedicle $[4,5]$. The interest of this observation is to report a new typical case and to recall and to discuss the diagnostic and surgical approach with the litterature.

\section{Observation}

A 27-year-old woman consults for afebrile chronic pelvic pain. Clinical examination finds a painful and fixed pelvic mass. The abdominal ultrasound discovered a vacuity of the splenic lodge, and a homogeneous tissue formation in hypogastric site. Elsewhere, no particularity has been noted. The abdominal CT scan revealed a homogeneous normal size liver with regular outline and undistended intra- and extrahepatic bile ducts, 
thin-walled gallbladder, a physiological splenic lodge occupied by digestive structures (Figure 1) and an homogeneous pancreas with regular contour and curved caudal portion along the splenic artery path to the hypogastric site (Figure 2). In the pelvic topography is localized a homogeneous tissue formation which takes "tiger" typical appearance at arterial time (Figure 3) corresponding to the spleen with normal size. The sagittal cross section showed the vascularization of the spleen by a branch of the celiac trunk (Figure 4) and the path of splenic artery to the pelvic wandering spleen (Figure 5). Otherwise, the uterus had a normal size with a homogeneous myometrium and a fine endometrium.

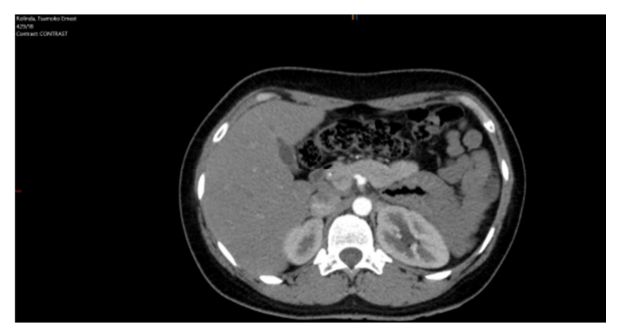

Figure 1. Arterial time of abdominopelvic CT with injection of iodized contrast (axial section): physiological splenic lodge is occupied by digestive structures including intestine and a normal topography of the head and body of the pancreas.

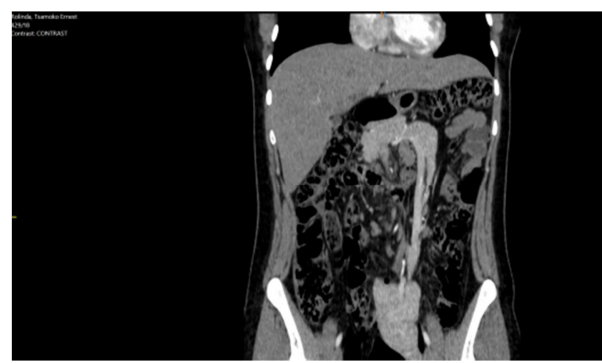

Figure 2. Arterial time of abdominopelvic CT with injection of iodized product (coronal section): the pancreas' tail following the spleen in the pelvis.

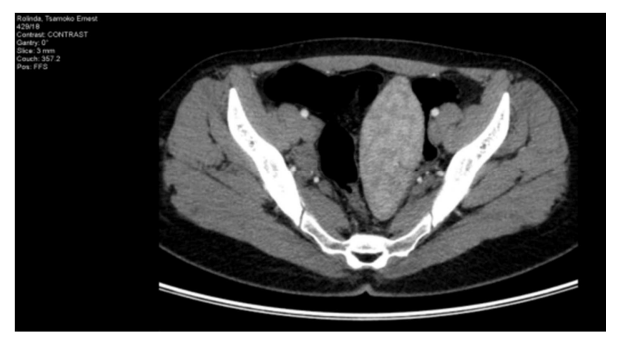

Figure 3. Arterial time of abdominopelvic CT with injection of iodized product (axial section): pelvic topography of the spleen with "tiger" typical appearance.

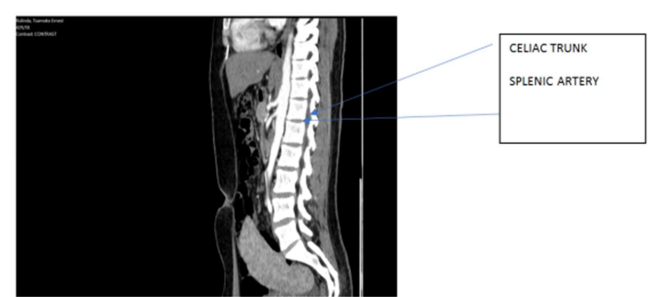

Figure 4. Arterial time of abdominopelvic CT with injection of iodized product (sagittal cross section): birth of the splenic artery on the celiac trunk.

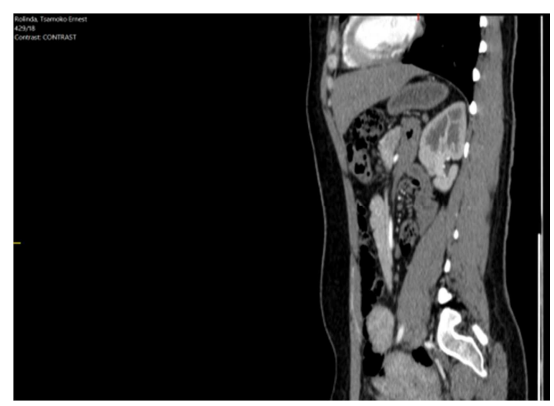

Figure 5. Arterial time of abdominopelvic CT with injection of iodized product (sagittal cross section): splenic artery follows the spleen in pelvic position.

Surgery by laparotomy was performed immediately, in the course of which the exploration confirmed the hypogastric site of the spleen. Splenectomy was done with smooth postoperative recoveries. And patient received immunization coverage against Streptococcus pneumoniae and Haemophilus influenzae after two weeks.

\section{Discussion}

Ectopic spleen is rare, less than $0.5 \%$ of several large series splenectomies $[1,2]$. It exists at any age, with predominance at male children under 10 years old, at women during genital activity period, between 20 and 40 years of age $[1,6]$, at the third decade of life, and at patient without particular medical history [1, 4, 5, 7, 8]. Only intraperitoneal localization is described, with hypogastric or pelvic predilection [4].

Congenital drifting spleen is due to the lack, uncompleted development or laxitude of the dorsal mesogastrium suspensory ligaments $[2,7,9]$. Acquired forms may be due to gastric distention, splenomegaly, abdominal hyperlaxity or weakness of the abdominal wall tone, abdominal injury, or hormonal change during pregnancy and multiparity $[4,5,10]$. Ectopic spleen can be associated with accessory spleen in $10 \%$ of cases [9]. Torsion of the splenic pedicle is the most feared complication in ectopic spleen, and it is fostered by pedicle length, mobility, and spleen weight [7, 11]. Infection and trauma were also cited as complication [1].

Wandering spleen may remain asymptomatic for a long time, or presents abdominal discomfort [1]. Then, it will be discovered in many variable circumstances, dominated by torsion complication's expression as abdominal, pelvic or peri-umbilical intermittent pain, or unfortunately during a complementary examination performed for other pathology [4, $5,8]$. Nausea, vomiting, fever, or splenomegaly can also go with torsion $[2,7]$. Physical examination may discover a firm, smooth, matt, painful and mobile pelvic or abdominal mass [1]. In tropical countries as Madagascar, these signs can bring confusion with parasitic splenomegaly, abdominal-pelvic tumor, chronic volvulus or a compressive obstructive syndrome $[5,12]$. General state alteration, anemia from hypersplenism, and toxi-infection's signs can occure in the severe form $[4,12]$.

The imaging is fundamental by showing the splenic lodge emptiness, the spleen's site and its size, and an eventual 
existence of accessory spleen [2, 8, 11, 13-15]. Ultrasonography, color Doppler, nuclear scintigraphy whith Technetium-99m, Computed Tomography (CT) angioscan and Magnetic Resonance Imaging (MRI) can be complementary [1, $2,8,14,15]$. Hypointense or isointense signal can be reported by MRI, especially needed in presence of accessory spleen [13]. Splenomegaly is possible in the presence of intermittent or acute torsion [2]. In developing country as Madagascar, abdominopelvic ultrasonography stays the most accessible referential imaging examination for its easiness to perform and its low cost. It shows the hypoechoic homogenous mass. Else, unfortunately less available, abdominal CT should be able to highlight the spleen's normal heterogeneity [14], with the vessels' specific spiral appearance at the arterial phase and their homogenization at the portal time, due to lack of gastrolienal, pancreatico-splenic and splenocolic ligament, as described in literature $[2,11,12]$. The pedicle torsion is suspected in occurrence of acute abdominal pain associated with amputation of splenic arterial perfusion and a whirlwind appearance of twisted pedicle (angioscan, Doppler) [5, 12]. In Mahabubnagar Inde, Ultrasonography is the investigation of choice [1].

Histopathological examination can distinguish a spleen tissue including capsule (100x), interspersed sinusoids (40x or $100 \mathrm{x})$, central arteriole $(100 \mathrm{x})$, lymphoid follicles $(100 \mathrm{x}$ or 200x) [13, 14].

Once the diagnosis is confirmed, surgical exploration should be performed to avoid complications [7, 11]. The choice of procedure is controversial for uncomplicated ectopic spleen: either a splenopexy into its normal anatomical position, or a splenectomy. Splenopexy risks till $65 \%$ rates for torsion's recurrence, so systematic splenectomy was considered as the only valid treatment to avoid complications $[7,8]$. Systematic splenectomy may expose to infectious complications, with $3.16 \%$ to $6.25 \%$ postoperative mortality by septicemia [16]. Indian team recommends splenectomy only in case of infarction [1]. Italian team reports an uneventful postoperative recovery after laparoscopic way splenectomy for a combined wandering and accessory spleens case, till patient releasing after 6 days [6]. Peduncle's ligations by endoclips, arterial before veinous, were followed by extraction through a pfannenstil incision [6]. Laparascopy technique stays to be developed in our country. However, in front of superficial necrotic colorations on twisted spleen, splenectomy should be systematically performed if the perfusion of the spleen could not be restored after torsion releasing [11].

\section{Conclusion}

In our precarious context, the diagnosis of an ectopic spleen still stays a challenge, because of its natural latence and the low accessibility of the patients to high-performance imaging. And because of the high endemic rate of tropical parasitic splenomegaly as differential diagnose, the systematic splenectomy followed by immunization should be the worthwhile decision from the beginning, even for uncomplicated diagnosed case, to avoid incurring risks of later unpredictable complication. Laparoscopy technique seems ideal for uneventful recovery but also stays to be developed.

\section{References}

[1] S Ramadugu, LR Chigicherla, VRR Kuchukulla, MR Satyanarayana, KRG Rama. Ectopic spleen - A case report. J Evid Based Med Healthc 2017; 4 (25): 1495-7.

[2] D Rodríguez Vargas, MJ Parada Blázquez, B Vargas Serrano. Diagnóstico por imagen de anomalías en el número y localización del bazo. Radiología 2019; 61: 26-34.

[3] Varga I, Babala J, Kachlik D. Anatomic variations of the spleen: current state of terminology, classification, and embryological background. Surg Radiol Anat. 2018; 40: 21-9.

[4] NJ Ahoury, KP N'zi, KA Kanga, FA Salami, AS Diabaté, AR Seka. Diagnostic d'une rate baladeuse par la tomodensitométrie multicoupes. J. Afr. Hépatol. Gastroentérol. 2016, 10: 167-169.

[5] T Dossouvi, B N'timon, K Adabra, M Dagbe, G Botcho, P Leyman et al. Torsion d'une rate ectopique: à propos d'un cas au chu kara (Togo). Mali Médical 2016, 31 (4): 44-47.

[6] A Rizzuto, SDi Saverio. Laparoscopic splenectomy for a simultaneous wandering spleen along with an ectopic accessory spleen. Case report and review of the literature. International Journal of Surgery Case Reports 2018, 43: 36-40.

[7] M Nyundo, F Ntirenganya, JC Byiringiro, G Ntakiyiruta, J Gashegu. Torsion d'une rate ectopique se présentant comme un abdomen aigu. Rev med brux 2011; 32: 477-479.

[8] K Blouhos, K A Boulas, I Salpigktidis, N Barettas, A Hatzigeorgiadis. Ectopic spleen: An easily identifiable but commonly undiagnosed entity until manifestation of complications. Int J Surg Case Rep 2014; 5 (8): 451-454.

[9] S Merran, PKarila-cohen, V Servois. Scanographie de la rate: anatomie normale, variantes et pièges. Journal de radiologie 2007, 88 (4): 549-558.

[10] Y Niu, W Liu, L Xian, T Liu, C Huang, S Yang. Thoracic splenosis presenting as pulmonary space-occupying lesion. BMC Surgery 2018, 18: 119.

[11] K Elhattabi, F Bensardi, R Lefriyekh, A Fadil, M Lahkim, N Benissa et al. Abdomen aigu sur une torsion de rate ectopique: à propos d'un cas. Pan African Medical Journal 2012; 11: $62-65$.

[12] JF Salem, F Tannouri, F Salem. Histoire d'une rate errante: un cas rare d'abdomen aigu. J medliban 2011, 59 (3): 170-172.

[13] N Marwah, N Bhutania, R Kalraa, P Kajal. Journal of Pediatric Surgery Case Reports 2019; 42: 19-23.

[14] AS Zugail, YAhallal, EM Comperat, B Guillonneau. Splenorenal fusion mimicking renal cancer: One case report and literature review. Urol Ann 2019; 11: 211-3.

[15] G Gayer, R Zissin, S Apter, E Atar, O Portnoy, Y Itzchak. CT findings in congenital anomalies of the spleen. Br J Radiol 2001; 74: 767-772.

[16] KG Koffi, I Sanogo, AH Toure, OT Allangba, D N'dri Oka, C Aguehounde et al. Indications des splénectomies au cours des hémoglobinopathies majeures: à propos de 21 cas. Médecine d'Afrique Noire: 2000, 47 (10): 426-429. 